\title{
Getting into the ACT with Psychoanalytic Therapy: The Case of "Daniel"
}

\section{ROBERT COHEN ${ }^{\mathrm{a}, \mathrm{b}}$}

\author{
a Madonna University and University of Michigan \\ ${ }^{\mathrm{b}}$ Correspondence regarding this article should be sent to Robert Cohen, 300 North Fifth Avenue,Suite 220, Ann \\ Arbor, MI 48104 \\ Email:rcohen1101@gmail.com \\ Acknowledgement. This case study is based on an earlier version presented to Paul Wachtel before the Michigan \\ Council for Psychoanalysis and Psychotherapy, November 2013, and later presented at the annual meeting of the \\ Society for the Exploration of Psychotherapy Integration (SEPI) in Montreal, May 2014.
}

\begin{abstract}
Daniel is a 44-year-old Caucasian male who has struggled with chronic depression and extreme sensitivity to feeling judged and criticized. I have seen him for more than ten years in psychoanalytic therapy. While he made significant progress in understanding the childhood determinants of his difficulties and achieved some symptom improvement, Daniel continued to struggle with observing and tolerating his feelings. This case study demonstrates how my decision to integrate techniques from Acceptance and Commitment Therapy (ACT; Hayes, 2005), a contemporary form of cognitive behavioral therapy, broke an impasse in the treatment, allowed the patient to resolve outstanding difficulties, and helped him move towards termination. The case report discusses the challenges of integrating ACT into psychoanalytic work, as well as ways that a psychoanalytic understanding of Daniel's resistance to ACT techniques made that treatment effective.
\end{abstract}

Key words: psychoanalysis; acceptance and commitment therapy; cognitive therapy; cognitive behavior therapy; psychotherapy integration; mindfulness; acceptance; defense (resistance) analysis; case study; clinical case study

\section{INTRODUCTION}

For many years cognitive behavioral therapy (CBT) has been considered incompatible with psychoanalytic treatment. The two approaches are often seen as leading to radically different therapeutic conceptualization and technique (Blagys \& Hilsenroth 2002; Milton, 2001; Pilecki, Thoma \& McKay, 2013). ${ }^{1}$ But with the emergence of so called "Third Wave” CBT

\footnotetext{
${ }^{1}$ Though the perspectives have often clashed, there have been a number of noteworthy efforts to make cognitive therapy more psychoanalytic (Young, Klosko \& Weishaar, 2003; Ryle, 2002) and to bring cognitive techniques into psychoanalysis (Connors, 1999; Bresler, 2015; Frank, 1990; Northcut \& Heller, 1999; Shanok, 2015; Stricker, 2006).
} 
approaches (Hayes, 2004), it has become possible to combine the explanatory power of psychoanalysis with a CBT approach that includes practical, behaviorally focused interventions. ${ }^{2}$

Wachtel 's (1977) pioneering effort to integrate psychoanalysis and behavioral therapy in the seventies catalyzed the psychotherapy integration movement. But when cognitive behavioral therapy supplanted behavior therapy, Wachtel concluded that fruitful integration with psychoanalytic therapy was no longer tenable. He observed that traditional cognitive therapy, with its focus on demonstrating the client's "faulty and unrealistic" assumptions, does not fit well with the contemporary psychoanalytic emphasis on opening up towards irrational thoughts and the acceptance of seemingly illogical feelings and fantasies. But newer CBT approaches converge with psychoanalysis in asserting the importance of accepting rather than avoiding or critiquing ideas or feelings that might be labeled illogical. As Wachtel (2011a) wrote, "Both aim to enter into the patient's experience rather than critiquing it, and both root the therapeutic effort in the dialectic between accepting the patient's experience of the world and helping him to change those features of his assumptive world that are contributing to his pain" (p. 16).

In spite of this compatibility, few clinicians have discussed the possibility of bringing together psychoanalytic approaches with perhaps the most prominent third-wave approach to cognitive behavior therapy, Acceptance and Commitment Therapy (ACT; Hayes, 2005). ${ }^{3}$ As a result, there are no in-depth case reports demonstrating the achievement of such integration. In this paper, I describe my experience introducing ACT into long-term psychoanalytic work with a 44-year old man struggling with chronic anxiety, depression and narcissistic vulnerability. The use of ACT within the existing psychoanalytic framework allowed the patient to work through an impasse that had made it difficult for him to complete treatment. The case shows the way a psychoanalytic formulation and its approach to working with resistance and defense allowed the patient to effectively make use of ACT techniques that he initially found quite challenging. And

\footnotetext{
${ }^{2}$ The label "third wave" was coined by Hayes (2004) to describe the emergence of ACT and other similar therapies. The "first wave" describes the initial conception of behavioral therapy as an attempt to apply sound empirical principles to therapy in contrast to what behaviorists found to be the implausible clinical explanations of psychoanalysis. It focused on modifying behavior without much reference to mental processes using techniques based on classical and operant conditioning. The "second wave," which describes the most prevalent behavioral therapy practiced today, emphasized cognition and focused on helping patients identify and dispute irrational thoughts that were believed to be at the heart of their difficulties. The "third wave" acknowledges the success of CBT, but posits that effective and lasting changes come not from changing the content of thoughts, but focusing on helping patients become aware of the context of thoughts (e.g., that thoughts are internally generated products of the mind and not necessarily true statements about the world). Third wave approaches focus on "metacognition, cognitive fusion, emotions, acceptance, mindfulness, dialectics, spirituality and therapeutic relationship" (Kahl, 2012, p. 523). Third wave approaches include ACT, Dialectical Behavior Therapy (DBT) (Linehan, 1993), Functional Analytic Therapy (FAP)(Kohlenberg \& Tsai, 1991), and Mindfulness Based Cognitive Therapy (MBCT) (Segal, Williams \& Teasdale, 2013).

${ }^{3}$ After I had presented an early version of this case report, Stewart (2014) published an edited volume on the integration of relational psychoanalysis with mindfulness, Buddhism, compassion and FAP. Two chapters focus specifically on integrating psychoanalysis with ACT, and appear to be the first published accounts of such a combination. The chapters include brief case vignettes.
} 
it shows that the practical, active approach to dealing with troubling affects and ideas advocated by ACT made it possible to help a patient make progress when analytic work had plateaued.

\section{CASE CONTEXT AND METHOD}

\section{A. The Clinical Setting in Which the Case Took Place}

For more than 20 years I have had a private psychotherapy practice in Ann Arbor, Michigan seeing between ten to 20 clinical hours a week. Having been trained in a psychoanalytically oriented graduate program and completing a post-doctoral fellowship in a dynamically based inpatient setting, I have tried to work as intensively as possible, seeing many clients twice or three times a week. In 2001, I began training as a candidate at the Michigan Psychoanalytic Institute, graduating in 2008. During this period I saw some individuals four or five days a week, using the analytic couch. In spite of this background, I have been fairly flexible, seeing many people once a week and also seeing children, couples and families.

\section{B. The Rationale for Selecting This Particular Client for Study}

I chose to report the case of Daniel because I had decided to do something rather unusual for a psychoanalyst: after seeing the client for years in a traditional psychoanalytic manner I decided to add some techniques from ACT.

I had considered incorporating techniques from an alternative therapy approach with some trepidation. A voice coming from my psychoanalytic superego rose in protest: Be careful, it cautioned, perhaps you are colluding with the patient's resistance. By becoming more active and directive, you might shut down the patient's ability to fully explore and gain insight into his difficulties.

Another voice made we wonder if my urge to change approaches was a way to avoid acknowledging that we had come as far as we could together. While we had made good progress over the years and had a good therapeutic relationship, did I need to consider that when a treatment lasts this long and there are still significant difficulties, a referral to another therapist was in order? And what would it be like for the patient if I were to broach this possibility?

The case illustrates, I think, some important aspects of integrative work. First, whatever use I've made of ACT has been done with what Paul Wachtel (2012, personal communication) calls "a psychoanalytic accent.” When difficulties emerged, I was able to understand and interpret the interferences based on my previous psychodynamic understanding of the patient.

And second, the process of using unfamiliar techniques and approaches is uncomfortable for those trained primarily in one approach (Bresler, 2015). Not only does doing so seem to violate the "rules" of psychoanalytic therapy, but it requires the willingness to tolerate unfamiliar modes of interaction as well. I suspect many therapists stick to their "home" theories out of a fear of such discomfort, even when there are indications that gains are no longer being made using their familiar techniques. 


\section{Sources of Data Available Concerning the Client}

As is typical of long-term psychoanalytic cases, the data available consisted of my detailed session notes and feedback from supervision and consultation that occurred during the early phases of the treatment.

\section{The Methodological Strategies Employed for Enhancing the Rigor of the Study}

Daniel was seen in ordinary clinical practice without, at the time of treatment, plans for publication of his case. It would, of course, have been ideal if the sessions had been audiotaped or videotaped, or if the sessions could have in some other way independently documented to create a more objective database. On the other hand, using such documentation is not the usual practice in psychoanalytic therapy, especially in a private practice setting. This reflects in part the culture of the psychoanalytic approach: until recently, the need for objective data to verify formulations, track the process of change, and objectively measure outcomes was seen as unnecessary and perhaps even counterproductive (Summers, 2012). The data most prized by the contemporary psychoanalyst was the intersubjective experience of working with the client in the consulting room, including the therapist's emotional responses to the client (sometimes termed countertransference). Recently such attitudes appear to be changing among some psychoanalytic practitioners, (Levy \& Ablon, 2009; Summers \& Barber, 2009) though there are still vehement objections (Hoffman, 2009).

Ongoing monitoring of my responses to the patient as part of a self-analytic process has helped to make the therapy less subjectively embedded in my own experience and thus, perhaps, more “objective.” But many analysts doubt that such objectivity is possible or even desirable (Renik, 1993).

\section{E. Confidentiality}

Confidentiality was maintained by including no information in the text by which the patient could be identified. Information that might risk identification has been disguised, while remaining as true to the process and dynamics of the case as possible.

\section{THE CLIENT}

As noted, Daniel is a 44 year old single white male whom I had seen for more than 10 years in twice a week psychoanalytic therapy at the point I introduced ACT. He entered the therapy suffering from anxiety and depression connected to problems in work and relationships. These difficulties had improved significantly during our work together and he now was successful in a job he enjoyed. He was in a relationship with a woman with whom he increasingly felt secure and committed. In spite of those gains, the treatment continued because the patient was still prone to rumination about his self-worth and at times experienced paralyzing discomfort and shame in relationships with friends and colleagues. 


\section{GUIDING CONCEPTION WITH RESEARCH AND CLINICAL EXPERIENCE SUPPORT}

Many clinicians using a psychoanalytic approach share a few key beliefs (Auchincloss, 2015; McWilliams, 2004; Mitchell and Black 1996). They include: 1) The patient's difficulties reflect unconscious forces shaped by temperament and the environment of early childhood; 2) Those unconscious forces conflict with the individual's internalized sense of morality and the circumstances of reality, leading to conflicts between these trends that result in psychological problems; 3) Patients reveal conflicts between those forces most clearly in the relationships they establish with their therapists (the transference), in which they repeat the habitual, self-defeating patterns they established in childhood as the best way to resolve crucial universal dilemmas; and 4) The more a therapy enables the patient to gain insight into their repetitive patterns and the underlying causes, the more effective and permanent the therapeutic gains will be. An increasing number of well-designed studies has shown that treatments subscribing to these basic principles are effective and, in many cases, lead to outcomes comparable to widely known empirically supported therapies, such as Cognitive Behavioral Therapy (Cuijpers, et. al, 2008; deMaat et. al, 2013; Gerber et. al, 2011; Leichsenring and Rabung, 2011; Shedler, 2010).

Analytic therapists, however, differ among themselves in important ways in their understanding of the most important unconscious forces at play and the most effective therapeutic techniques to resolve patients' conflicts. "Classical," or Freudian analysts are sodescribed because of their adherence to certain parts of the theory emphasized by Freud, the founder of psychoanalysis (Arlow and Brenner, 1964; Brenner, 1982; Ellman, Grand, Silvan \& Ellman, 1998). This group of analysts emphasize the importance of Freud's dual instinct (drive) theory which emphasizes the role of innate sexual or aggressive drives in the shaping of psychopathology. When drives are either defended against too rigidly or are not contained enough to prevent destructive action, psychological suffering occurs. Patients who seek psychoanalytic treatment often show maladaptive defenses in which early experiences have led them to defend in painful, self-depriving and self-defeating ways against feelings of anger or wishes for sexual gratification (Freud, A., 1936/1966; Valliant, 1993).

Therapeutic technique, from this perspective, is designed to maximize access to drive related material in the therapy. Frequent sessions, usually four or five per week, the use of the couch, and the analyst's restrained presence are thought to make the drive material more accessible. The analyst then focuses on "interpreting” the patient's defensive efforts to avoid expression or acknowledgement of drive related wishes. The most vivid appearance of driverelated material appears in the transference. It was once thought that analysts could heighten transference feelings and make them more available for interpretation by abstaining from giving advice or direction and remaining as anonymous as possible (Lindon, 1994; Renik, 1995). These measures, it was believed, would allow the patient to project as much as possible of his or her own psychological experiences onto the analyst and make these drive-related unconscious experiences observable; as a result the theory precluded active interventions in which the analyst taught new skills, suggested activities to be completed between sessions, or provided too much encouragement. The chief mechanism of change in this model is insight into the historical circumstances and the current manifestations of those events that have led the patient to repress, 
distort, project, or act out drive-related wishes and ideas. The patient identifies with and internalizes the analyst's reflective and interpretive attitude, allowing the patient to respond to conflict and difficulty through self-understanding that lessens the impact of early, drive related experiences (Strachey, 1926; Loewald, 1960; Sugarman, 2006).

Other theoretical approaches have de-emphasized the role of drives and the need for the analyst's role to be so restricted. One of the most influential has been the Relational approach, which has developed from aspects of both the Object Relations, Self-psychological and Interpersonal psychoanalytic traditions (Greenberg and Mitchell, 1983; Wachtel, 2008). This theory posits that people are motivated more by their needs for relationships rather than gratification of drives. Influenced by attachment theory (Wallin, 2007), which studies the important ways early childhood experience is shaped by the adaptive need to find secure emotional responsiveness in caregivers, Relational approaches focus on the way early traumatic or mis-attuned experiences in a child's relationship with primary caregivers create problematic patterns that negatively affect current relationships. Therapeutic technique, from this perspective, still values the role of insight but highlights the potential to form an authentic, emotionally rich relationship with the analyst as a corrective against early experiences of deprivation or dissatisfaction (Stern et. al 1988). As a result the therapeutic relationship is not as restrained and one-sided as that found in more classical approaches. Relational analysts have focused extensively on the psychology of the analyst and the way she inevitably brings important aspects of her own relationship history into the room with the patient (Aron, 1991; Hoffman, 1983). As a result, the analyst is less of detached observer of the therapeutic experience and more an active participant who needs to acknowledge the way his or her own relational struggles influence the therapeutic relationship. In recent years, some classical practitioners have been strongly influenced by the Relational approach. These analysts have accepted the Relational schools belief in the impossibility of being a blank slate onto which patients project their own experiences. As a result, even contemporary Freudian analysts conform less to the stereotypic silent analyst behind the couch (Jacobs, 2013; Renik, 1995).

The approach I brought to Daniel's treatment drew from the classical tradition in which I was trained both in graduate school and in psychoanalytic training. However, as Relational ideas entered the psychoanalytic mainstream in recent years, I became less restrained and more affectively present with my patients, including Daniel. A way to describe this change would be to say that I moved from an exclusive focus on providing insight to what many refer to as a more supportive therapy in which I became more of accepting, empathic mentor. ${ }^{4}$ The move away from the classical approach in the field also coincides with the increasing acceptance among psychoanalysts that insight often is not sufficient and something is curative about the relationship itself. In the 1950s and 1960s, classical analysts criticized the idea that a "corrective emotional

\footnotetext{
${ }^{4}$ Classical analysts have demeaned more supportive therapy as a form of treatment best suited to those patients who are either too disturbed or don't have the requisite self-reflective capacities as do higher functioning individuals who will benefit most from insight-oriented treatment (also referred to as expressive psychotherapy). A common clinical adage reflecting this belief states: "Be as expressive as you can be and as supportive as you have to be” (Wallerstein, 1989, p.203). Wachtel (2008), writing from an integrative, relational psychoanalytic approach, has criticized this guideline as leading therapists to limit the type of interventions they use in ways that work against therapeutic change.
} 
experience" with the analyst was as important or even more important than interpretation and insight (Wachtel, 2008). But with the increasing popularity of theories that depart from the classical position and the influence of research on the importance of attachment throughout the lifecycle, the curative role of the relationship with the analyst is widely acknowledged (Gabbard \& Westen, 2003; Pulver, 1993).

In addition, my approach has been influenced by the psychotherapy integration movement, which has recognized the limits of the traditional separation of therapeutic theories into isolated "schools" that do not attend to developments in other approaches (Norcross \& Goldfried, 2005). The approach I report using in this paper would be characterized as Assimilative Integration, one of several approaches to integration identified by leaders of the integration movement (e.g., Messer, 1992). Assimilative Integration, as described by Messer (2001), "... is the incorporation of attitudes, perspectives, or techniques from an auxiliary therapy into a therapist's primary, grounding approach" (p. 1). The case presented here vividly illustrates the reasons for turning to an Assimilative Integration approach.

ACT is based on the idea that finding a way to observe and accept upsetting experiences doesn't eliminate them, but allows people to live with them and go on to pursue what is really important to them. The therapy elucidates the counterproductive nature of what is termed "Experiential Avoidance" — what dynamically oriented clinicians would term defense-and helps patients practice accepting thoughts using mindfulness techniques and other exercises. Another important component is helping people identify goals and values and then commit to active efforts to achieve them. Doing so provides individuals with the motivation to live with their distress in order to accomplish what is most important to them.

ACT, like other cognitive behavioral therapies, is quite active and draws on a number of experiential exercises, but in my view, its goals are quite consonant with psychodynamic treatment. I first heard about ACT some years ago from an analytic patient who read about the therapy in an article in Time magazine (Cloud, 2006). This patient noted its similarity to the work we were doing. She said the ACT framework helped her understand better what was happening in our sessions. As I learned more about ACT, I thought it might be helpful to Daniel as well.

\section{ASSESSMENT OF THE CLIENT'S PROBLEMS, GOALS, STRENGTHS, AND HISTORY}

\section{Mental Status}

A small but fit man with dark features, Daniel usually enters sessions appearing calm, with no apparent affect, but can quickly sink into morose and ruminative states in which he closes into himself. From the start of our relationship it was clear he is highly intelligent, with a quick wit, and when we shared pleasure in a joke he laughed freely and enthusiastically. Only rarely has he allowed his sadness to become manifest in tears. 


\section{Presenting Problem and Goals}

Daniel's initial presentation was marked by seemingly equal amounts of troubling anxiety and depression. His anxiety concerned his uncertainty of whether he could work with me, fear of committing to his current girlfriend, and a sense that if moved ahead in his career he would be overwhelmed and incompetent. Depression was evident in his reports of persistent low mood, poor self-esteem and negative self-evaluation, and the affectless way he presented in the initial sessions, as noted above.

General therapeutic goals seemed fairly obvious from Daniel's initial presentation: he wished to feel more confident in work and relationships and feel less paralyzed by worry and the negative feelings he had about himself.

\section{Previous Therapy}

Daniel was referred to me for psychotherapy after he had been treated successively by four therapists in a low-fee university run training agency over a period of four years. Each time a trainee completed his or her time at the agency, Daniel accepted a referral to another trainee. Daniel had found some of the work with these therapists helpful, but finally, one of his therapists suggested he seek treatment in the community so he wouldn't need to keep starting over. He agreed with the recommendation and pursued a referral to me from that therapist.

\section{Developmental History}

Daniel is an only child whose life growing up was often quite lonely: he had few close friends and at times was bullied by tough boys in the lower-middle-class community where he was raised. Though he recalled fond memories of playing with his father as a young child, the patient often found him frightening. He described his father as volatile man, capable of explosive tantrums, who often retreated to the bar; Daniel recalls one incident when his father picked him up and threw him onto the couch, but has no other memories of physical abuse. He is dimly aware that his father had some psychiatric problems that led him to be hospitalized several times in childhood, but the patient didn't know enough about those experiences for me to get a sense of his father's diagnosis. Daniel's father never was able to hold a job for any length of time and the family was supported by Daniel's mother, who worked as a secretary to a high level administrator in a local non-profit agency. He described a positive attachment to her, but he remembered how she suffered from headaches and was often in bed and unavailable to him.

Daniel reported a history of academic success and recognition for his ability to write in high school, but he struggled in college, often paralyzed by long bouts of procrastination. Other important aspects of Daniel's early development emerged over the course of treatment and will be detailed below. 


\section{History of Romantic Relationships}

When the patient first started seeing me, he had been in a four-year relationship with a woman he met in the waiting room of the low-fee therapy clinic where he had been a patient. They were drawn to each other by their ability to understand each other's depression. But Daniel eventually came to feel that while she comforted him when he was depressed, he didn't feel she really desired him, especially sexually. She could be quite critical and demeaning of him, leading him to feel narcissistically wounded. He imagined if he broke up and dated others, he would find women who would be more excited by him. After a great deal of self-doubt, he broke up and spent several years dating a number of women with whom he often felt similar disappointment.

Eventually, he met Janice, a woman who in many ways is similar to his first girlfriend. She can also be critical of the patient, and is highly sensitive herself. A victim of physical abuse in childhood, she becomes anxious and critical if she feels the patient is being overly aggressive. When Daniel feels he's being direct and assertive, Janice often says she feels scared; she highlights what she sees as an angry expression on Daniel's face, even when he's not aware of feeling angry. Janice's complaints have brought up strong feelings of shame and guilt, for Daniel has long been concerned about experiencing and expressing angry feelings, especially with women.

\section{Strengths}

In spite of his difficulties, it was apparent from the outset that Daniel was a bright, curious individual who valued his intellect, even if he complained he didn't get to use it as much as he liked in his jobs. He often complained about the demands of work, but, in contrast to his father, had been able to hold onto various jobs and appeared capable of much more if he could get past his inhibitions.

\section{Diagnosis}

Like most analytically inclined clinicians, I don't believe DSM diagnosis offers much helpful explanatory power for the work I do, since the focus on surface level symptoms does not augment an understanding based on patterns of memory, feeling and thoughts, some of which are unconscious. When Daniel started therapy, he was already taking an antidepressant which provided him minimal relief, but protected him against severe mood dips. Pressed to locate Daniel's condition in the DSM-5, his difficulties seem best captured by Persistent Depressive Disorder, with some periods in which he would meet criteria for Major Depressive disorder.

A more helpful categorization comes from the Psychodynamic Diagnostic Manual (PDM Task Force, 2006) which was written to complement DSM-IV by outlining conditions that psychoanalytic clinicians might recognize. It provides information about underlying dynamics and the subjective experience of the disorders. In the PDM, Daniel would fall under the category of Depressive Personality Disorder, Introjective type, which accounts for the pervasive and persistent nature of his depression, and his severe self-criticism. Given his sensitivity to criticism 
by others, another appropriate category would be the PDM's Narcissistic Personality Disorder, Depressed-Depleted Subtype. ${ }^{5}$

\section{FORMULATION AND TREATMENT PLAN}

The initial assessment and early therapy sessions with Daniel revealed a palpable sense of narcissistic vulnerability. Much of his depression stemmed from his sense of himself as inadequate and thus incapable of being loved and cared for; he appeared to experience a great deal of shame about revealing himself, fearing he'd be exposed as ineffective and unworthy. Following the psychoanalytic conception used in this case, my understanding was that these attitudes often were not conscious, but evident just below the surface of awareness. He was exquisitely sensitive to slights and often felt that he was about to be rejected. For instance, in the first consultation session, he became visibly troubled when I blew my nose and he asked me to avoid doing so in the future.

He also has struggled with difficulty applying himself to work, often wishing he could just relax and indulge in his hobbies. In the early years of treatment, he struggled in jobs, bored and irritated by the demands of work, and didn't function well as an employee. I understood this problem as likely reflecting an unconscious identification with his father, who struggled in similar ways at work. The work difficulties led him to feel guilty and fueled self-critical rumination.

I speculated that Daniel feared being too assertively successful, lest he anger and alienate his father, resulting in punishment and loss of his connection with him. Following the drive model outlined earlier, Daniel needed to defend against awareness and expression of his aggression. Beating his father by excelling at work, in my view, threatened to elicit additional angry and critical responses from his father, whom he didn't want to push away further. By refraining from doing better than his father, Daniel had unconsciously settled on a strategy of joining rather than beating him. Much of the anger he felt about how his father treated him appeared to be self-directed, leading Daniel to ruminate in a self-critical way and sabotage his success. This formulation, deriving from a classical psychoanalytic perspective, suggested useful areas for investigation and interpretation and helped me understand Daniel's early hesitation to express annoyance and disagreement with me.

Early in the treatment, I considered the possibility of offering Daniel formal psychoanalysis (four or five sessions a week on the couch) as part of my psychoanalytic training. Noting that the patient struggled to experience strong affects, one supervisor I consulted was hesitant to suggest such a change. I did eventually mention the possibility to Daniel; he was not open to the idea and, given the impression of the supervisor, I did not strongly pursue this option. I thought that Daniel was quick to reject my suggestion, perhaps recognizing such a change

\footnotetext{
${ }^{5}$ This diagnosis describes a group of patients who experience themselves as damaged or deficient and are thin-skinned, frequently expecting to be slighted or dismissed. This is a form of narcissism not recognized in DSM-5, which highlights what the PDM terms an "Arrogant/Entitled Subtype" of narcissism. The depressed-depleted subtype of narcissism had been recognized by a number of clinicians (Gabbard, 1989; Levine \& Faust, 2013) before appearing in the PDM.
} 
would intensify his affective experience more than he thought he could manage. Further discussion did not change his mind.

Over the course of the treatment, as I became more relationally oriented, I realized that being restrained in my interaction with Daniel made it difficult for him to participate in therapy. I was also aware that he was seeking to connect with a less intimidating father-figure and that a more relaxed attitude, in which I focused on expressing empathy or engaged his sharp sense of humor by inserting humorous comments, was more effective in offering a model of a connection to others that might help correct for the difficult aspects of his earlier relationships. (This part of the treatment might have been seen as supportive, following the description mentioned above.)

\section{COURSE OF THERAPY}

\section{Co-Constructing a Picture and the Meaning of Daniel's Nuclear Family Experience}

Over the course of the therapy, Daniel has understood a great deal about the origins and meanings of his difficulties. Initially he was quite protective of his parents and unwilling to acknowledge any disappointment or anger with them. He was self-critical of such feelings, believing that they made him come across as a whining victim. But over time, with my frequent curiosity about his need to be so self-critical and my interest in understanding how his background contributed to these feelings, we have developed the following coherent narrative concerning the influence of his early experiences. ${ }^{6}$

Daniel's father, who appears to have struggled with a great deal of inadequacy himself, seems to have felt threatened by his son's successes. Daniel was a star student who completed his undergraduate degree before his father, who went back to school later in life. Daniel reported that his father demeaned his success; after the patient reported doing well on a particular assignment, he recalls his father stating: "Remember, all glory is fleeting." Another time, when Daniel froze with anxiety when he was supposed to play a solo at a musical competition, his father did not respond with sympathy, but told Daniel that maybe this was good for him because he was becoming too cocky.

Together we were able to understand that Daniel feared being too assertively successful, lest it anger and alienate his father, and result in punishment and loss of his connection with him. The anger he felt about being treated this way by his father was then self-directed, leading him to ruminate in a self-critical way and sabotage his success.

\footnotetext{
${ }^{6}$ The notion of co-constructing a narrative understanding is reminiscent of Constructivist Therapy (Neimeyer and Mahoney, 1995), in which the goal of treatment is to help the patient develop a coherent narrative as a way to reformulate in more useful ways the "stories" behind his or her symptoms. A similar framework has been developed by psychoanalytic therapists in which there is less concern with discovering the historical truth behind a patient's difficulties — which may be epistemologically impossible-- than in putting together a credible narrative of the patient's life story (Spence, 1982; Schafer, 1994).
} 
Over time, we also were able to understand the way he felt compelled to protect and care for his mother. Daniel initially avoided awareness of his critical feelings towards her. As a result, his mother still remains mostly an enigma. He has described her as mildly depressed during his childhood, and occasionally, he has reported critical and cutting remarks that she made. Daniel has become increasingly aware of negative feelings toward her, especially for the way she put up with his father's hostility.

We've come to understand Daniel's fears of assertion and anger as related to his worries about identifying with his father, especially the way his father could be hostile and threatening to his mother, whom Daniel felt obligated to protect. Awareness of this identification has been quite difficult for him but over time he has been able to better recognize that his tendency to identify with his father does not mean he must become him.

An important set of memories concerning Daniel's parents occurred when he was nine or ten. His father would come home drunk from the bar late at night and loudly fight with his mother, at times demanding sex. The patient would lie in his bed, awake and terrified. When his mother came in to check on him, he pretended to be asleep. When his mother nervously asked the patient the next morning if he had heard anything, he again lied, saying he had not. Over the years, he has come to look back on these experiences with irritation: he felt he had to suppress his reactions of fear in order not to worry his mother. And she was not able to help him with his terror.

One time, his mother woke him up because she was afraid of his father who was more out of control than usual. Daniel came into the living room, where the father had been breaking dishes. He found his father sitting distraught with his head in his hands, in his underwear, and the patient had to calm and soothe him. As a result of exploring these memories, Daniel has become aware of how difficult it is for him to feel comfortable with his own needs and how much pressure he feels to take care of others. He gets irritated if he feels a demand to take care of others, but it also clear that helping others can give him a great deal of pleasure.

\section{The Therapeutic Relationship}

In a psychoanalytic treatment of this length one might expect many of these important insights grew from work in the transference, but this doesn't appear to be the case, at least in any obvious or clear way. Daniel has never taken to exploring feelings about our relationship in any depth.

Daniel started seeing me after ending treatment with a female therapist he described as quite nurturing and he initially complained that I wasn't warm and sensitive in ways he expected. Though he never was able to state this directly, I also believe he was initially afraid of me and concerned he might elicit anger and criticism from me as he had with his father. My attempts to highlight how such expectations might color the way the patient experienced me rarely led the patient to explore this connection in an affectively alive way. He might intellectually acknowledge an idea, but come back to positive ways he viewed our relationship. 
Around vacations and interruptions Daniel has at times appeared more depressed, or would become more irritated with his partner, but my efforts to link those feelings to experiences of my absence rarely went anywhere. In a counterdependent way Daniel minimized feelings of missing me and often needed to downplay his wishes to rely on me for help. Though this hasn't come up for some time, Daniel often excoriated himself for being such a helpless dependent person who would need so much therapy.

Over time his attitude towards me has changed. He has come to describe talking with me as validating and sees the therapy as a refuge, the only place he really feels comfortable being open about himself. I have wondered to what extent Daniel feels compelled to praise me to protect me from critical feelings, in the way that he often felt compelled to take care of others in order to remain attached, and we have discussed this regularly. I suspect he has an even greater need to idealize me and identify with my acceptance of him and my wishes for him to do well (Kohut, 1971).

As stated earlier, the treatment has evolved over time into being more supportive. I've continued to bring him back to what we've understood about the roots of some of his difficulties with anger or closeness when these issues come up in current relationships. But I have also encouraged him to deal more forthrightly and directly with things that make him anxious. I have highlighted and celebrated his successes and pointed out his difficulties fully owning them.

\section{The Process During the Psychoanalytic Portion of Treatment}

The outcomes I described in the previous two sections emerged from therapeutic interactions focused on typical psychoanalytic approaches to exploring affect, highlighting resistances, and suggesting links between the present and the patient's past. The links I suggested-or "interpreted" — often led the patient to elaborate further aspects of his growing up that he had found too uncomfortable to reflect upon before they came up in therapy. Daniel began the session with whatever came to mind and I listened carefully to identify the material conveyed with the most affect or avoided most strenuously. For instance, if Daniel described an argument with his partner in which he felt criticized, but minimized any feelings of hurt or anger, I would gently inquire further into what he might be feeling. I might interpret his defense against experiencing any affects that he avoided by noting how difficult he found it to pay attention to certain feelings or thoughts that his associations suggested. Consistent with commonly understood principles of psychoanalytic technique (Cabaniss, 2013), I worked from the surface (those experiences closest to awareness) to depth (material strongly defended against and more frightening or challenging to recognize). While working this way allowed us to develop the understandings described above, the work often was painful, with Daniel harshly criticizing himself for perceived weaknesses and faults associated with the ideas and feelings he began to experience. For example, discovering that he was procrastinating at work because he had a wish to return to childhood, when he could "relax" and enjoy playing games, led to the expression of strong feelings of guilt and self-criticism and an urge to find some way to get rid of them. 


\section{The Situation at the Time I Added ACT}

As noted above, Daniel still struggled with periods of ruminative self-criticism. Over time, he became focused on an uncomfortable sense of being inept in relationships. When we first started working together, Daniel stated he couldn't relate well to men and only connected with women. But in recent years he had developed several male friendships. While there was no indication any of these new friends felt critically towards him, Daniel worried they found him boring. He longed for others to find him entertaining, smart and articulate. He heard his own speech as poorly expressed and ungrammatical, though I have always found him to be quite wellspoken.

So while he appeared more content in general than at any time I'd known him, Daniel still plunged into periods of feeling boring, undesirable, and hesitant to connect with others. There was also often a sense of being directionless: he felt lazy, didn't want to do things that took effort and indulged in fantasizes of sitting around playing games. Fortunately, these feelings no longer affected his functioning at work; around this time he was recognized with an award presented to outstanding employees. His relationship with Janice also appeared to be going better: in spite of conflicting feelings, Daniel showed commitment to working out disagreements with Janice and she has been less critical and more accepting of Daniel. They seemed fairly comfortable with each other, agreeing they didn't wish to marry or have children, but enjoyed living together. His mother had retired and his father appeared to be calmer and less reactive. His father hadn't had problems with drinking for many years.

Throughout the treatment, the patient had trouble experiencing and communicating uncomfortable feelings, especially embarrassment and anger. From the beginning, Daniel was convinced that if he allowed himself to experience a tough feeling, it would overwhelm him and force him to act in unacceptable ways that put off other people. The idea that he might feel his feeling and experience it as a valuable clue to his inner workings, even after all our work together, appeared alien. Though he was aware that aspects of his childhood made it advantageous for him to bury or distract himself from feelings, the idea that now, as an adult, he might be able to accept and experience them still seemed daunting.

Eventually, I concluded I had worked with his affective difficulties as best I could using a solely psychoanalytic approach. My focus on highlighting feelings and interpreting what might make them hard to tolerate and express based on his early challenging experiences did not help Daniel approach them with less trepidation. Psychoanalytically oriented readers may have ideas about what I may have missed, or could have done better. But as I mentioned above, my recent experience with psychotherapy integration led me to consider that techniques from other approaches might be effective.

I offered Daniel the chance to use ACT by following a workbook written by the founder of the treatment, Steven Hayes, entitled, Get Out of Your Mind and Into Your Life (2005). Daniel was intrigued by the approach. Though he found the book a bit "hokey," he thought it was worth a try. We have worked through various chapters, with him reading them on his own and then discussing them in sessions. I often asked him to try the experiential or written exercises in the book outside of session. Sometimes, Daniel found an exercise difficult and we 
would go over it together in the session, sometimes practicing them during our meetings. Many of the exercises involve guided mindfulness meditations. I led the exercises and we then discussed them. In the sessions I'll present it will be obvious that the idea of devoting time to the ACT book precipitates many of Daniel's conflicts about accomplishing things and brings to life his struggles with affect.

\section{Detailed Sessions With Daniel}

[My comments are in parentheses. Descriptions about the session and background information are in brackets. The flow of the session and the dialogue was reconstructed by me in detailed notes I made shortly after each meeting. ]

\section{$\underline{\text { Session } 1}$}

Daniel reveals that he forgot to bring his ACT book. Then he talks about his social discomfort, a common concern. He's dealing with a former employee who is coming back to give a talk to the newer hires. He's a big guy, super outgoing and social. Daniel always felt threatened by this guy, who he saw as easily able to interact socially; he never felt he could measure up. Daniel mentions another guy, Matt, with whom he had lunch recently. They talked about issues at Matt's job; Matt had recently switched to a new department and described all the difficulties in the new setting. When the conversation became focused on Daniel, he thought that Matt seemed bored. Matt also gave him a novel to read and he's been having trouble with it. He's not sure what to do: how can he tell him he doesn't like it? It's an experimental novel.

(I said, “It sounds like you don’t like those sorts of novels?”)

"No," he said. "We actually first bonded because we realized we both really like the same avant-garde novels. This led Matt to lend me the book I'm having trouble with. Matt also suggested we go out some time with the women. Matt even stopped by my house recently just to say hi."

(I said, “He is showing interest, yet something leads you to think he is bored?”)

"I know,” Daniel said. "I still think he is bored. Some other guys have been interested in hanging out with me too. One of the employees I supervise heard I was playing a new game that he and his friends play. It's all about negotiating, but there can be tension because you might have to betray people."

(I asked: “Is that hard for you?”)

“No, not a big deal at all,” Daniel said. “But I'm concerned about playing with people I supervise. ... it will be crossing boundaries. I want the employees to have their own space. I tell them that but they still want me to play." hesitant?”)

(I said, "I wonder, given their enthusiasm, if anything else leads you to feel so 
“I don’t know,” Daniel said. "It makes me feel like maybe I don’t really want to be with people. I know, I came up with the idea that one of my ACT goals was connecting with and helping people, ${ }^{7}$ but now I wonder if I only want to do that when I'm at work. In my off time I'd rather be on my own.”

(I said, "That might be so, but you said part of what bothered you was the idea you might be seen as boring. That seems to suggest it does matter to you whether you can connect with these people.”)

“That's true,” he said. "But this makes me think of that issue with the 'tell."” [Recently, he'd frequently used the metaphor of the "tell”- the way someone in a card game might inadvertently reveal their hand-to describe his concern that without meaning to, he might reveal unsavory parts of himself and push others away.] feelings?”)

(I said, "I wonder if you tried to use any of the ACT techniques with these ideas and

Daniel said, “I do, but I’m not sure I want to let go of these worries. If I don't pay attention to these critical worried feelings, I might do things or say things that I'll regret."

(I said, "I wonder if you can consider that you are fused with the idea that you are destined to get in trouble if you accept feelings and are not disturbed by them?”)

[Here I was referring to the ACT concept of fusion (Blackledge, 2015), which occurs when a person becomes so invested in a particular idea that they lose track that it is just a thought, a product of their own mind.]

“That's a good point,” Daniel said, “but it makes me very uncomfortable. I tried to do another ACT exercise where you locate yourself as an observer and non-judgmentally watch your thoughts and feelings, but it's hard to do that with these feelings. ${ }^{8}$ There is a part of me that doesn't really want to let go of my worries about my feelings. I don't know what could happen if I didn't worry."

\footnotetext{
${ }^{7}$ A core therapeutic task in ACT is helping patients identify their values and develop goals consistent with them. Individuals who struggle with psychological difficulties lose track of what motivates them and their behavior ends up being in the service of avoiding painful experiences rather than seeking meaningful satisfaction connected to their core desires (Harris, 2009).

8 The exercise, “Experientially I'm Not That” is from chapter seven (Hayes, 2005, p. 97).

${ }^{9}$ From an ACT perspective, Daniel's reluctance might suggest he was still fused with these ideas and needed more work with defusion. But psychodynamically, this process would be seen as working through his ambivalence, a frequent occurrence in therapy. Interestingly, working through ambivalence is a key aspect of Motivational Interviewing, which developed out of a client-centered perspective (Miller \& Rollnick, 2012).
} 


\section{$\underline{\text { Session } 2}$}

"Pretty good weekend,” Daniel said when he first came in. “Though I didn’t get to look at the workbook. I glanced at it this morning, briefly.”

(I asked if it is unpleasant or uncomfortable to work with it.)

"Yeah,” Daniel said. “The idea I'd have to feel all this stuff. It seems too painful. Though I still have been meditating."

[He then asked whether I have found another morning time for him. He comes early on Monday now and would like another day, so he could sleep later on his first day back to work after the weekend. I told him some time ago I would let him know if another appointment had opened, but nothing is available yet. The question reminds me of the times Daniel has felt that getting to therapy is too much work; if an appointment falls on a vacation day, he sometimes cancels so he doesn't have to get up early. Frequently Daniel arrives at the office quite early for the Monday appointment because that's when his bus arrives, and I find him waiting outside my suite door before I open up the office. I realized now that he wasn't as early as usual and ask about it.]

“Today," he said, "I waited at a coffee shop and looked at the ACT book. I was looking at the 'Willingness' chapter [Willingness is an ACT concept based on finding ways to be willing to accept discomfort when it is present]. I'm afraid if I have all these feelings, there might be a 'tell' and people will know what I feel and that will be embarrassing.”

(I said, “I wonder if this is related to the fears we were talking about last time?”)

Daniel said: "Probably. After I left here Friday, there was a presentation for the newer employees by that former employee. It went ok. The thing is, this guy is pretty friendly and it's hard to tell if he was really feeling warmly to me, or if that's just the way his is with everyone. I'm also thinking that I never got back to Matt, who came by the house. I'm ashamed of not getting back to him, but when I imagine feeling that shame, as ACT suggests, I worry I'd never feel any reason to call him back. I also hesitate to call him back because I don't want him to think I'm pursuing him too much. I don't want it to seem like I want a more intimate relationship. I did have experience with that before. [I understand him to mean a time many years ago when, after wondering for a short while if he might be attracted sexually to men, he went on a date with a man] .

(I said, "I remember that made you pretty nervous.”)

Daniel said, "Yes, it did. We didn’t do much together. There was just a kiss, a kiss in the car, just like what friends would do.”

(I said, "I wonder if it's not just that you are worried about being rejected and Matt won't like you, but I wonder if you are also concerned that if he's interested in you, maybe there could be more to it and that would make you even more nervous.”) 
He said, "I don't think this guy is interested in that kind of relationship; after all he is married. But the possibility he'll think I’m pursuing him does bother me.”

(I said, "Yes, it seems like you're afraid how your wishes to be close might be interpreted.”)

He sits with this, somewhat painfully. (I then said, "You spoke of being reluctant to come here today and work with the book, and maybe there are some similar feelings as well about not wanting to feel too close to me.”)

He said, "I guess that could be. But I'm thinking more about what to do about Matt's book. I don't like it. I'm still trying to read it, but I don't like it.” 10

\section{$\underline{\text { Session } 3}$}

Daniel begins by saying things are going pretty well. He did some work using the ACT book since we last met. He tried an exercise on Willingness that involves targeting a difficult feeling. He focused on feelings of being judged and inadequate. The exercise involves trying to visualize the painful thoughts and then trying to hold the image away from you and just let it be there, without pushing it away completely. The second part of the exercise is to visualize the defensive response the patient has to the painful feelings. He wasn't sure he did it right and he expresses uncertainty. ${ }^{11}$

[I asked if he would want to look at it together and see if I can help clarify it. We each look at our copies of the workbook.]

He states that the image he came up with was of a very awkward pimply young adolescent. That image, he said, stands for all of his feelings of being inadequate and embarrassed that are so difficult. For a defense, he visualized a set of concrete stairs that he could climb and then be over and above the pimply teen.

(I said, “These sound like really good responses. You really provide a useful, personal image of these feelings. I wonder how it was to hold these feelings out, as the exercise suggests?”)

Daniel said, “It was very difficult. It’s different from the meditation I do.”

\footnotetext{
${ }^{10}$ Listening psychoanalytically, Daniel's struggle with "the book" sounds like an allusion to the ACT book we are working with, which he may not like, but may feel pressure to approve of since I recommended it. Because the thought of upsetting me or complaining about me is aversive, the theory suggests he might displace those feelings onto an easier target, in this case Matt. Working with his feelings about Matt's book should help him feel more comfortable with whatever feelings he has about the book we are using. While Freud (1912/1958) famously noted that "it is impossible to destroy anyone in abstentia or effigy," contemporary analytic therapists find, especially when seeing patients once or twice weekly, that working with affects outside of the transference can be quite helpful (Wachtel, 2011b).

11 “Physicalizing," chapter 10 (Hayes 2005, p. 137).
} 
(I said, "I wonder if these sorts of thoughts come up in meditation, and can you notice them and return to your breathing?”)

Daniel said, “I try, but sometimes I get caught up in the feelings and don't return to my breath. I get caught up in the feelings and worry about the 'tell."”

(I said, "That really does sound difficult. I wonder if it might be useful to do one of the exercises that involves accepting feelings?”)

He looks in the book and selects an exercise that focuses on imagining difficult feelings floating away like leaves down the river. He decides to do it for a few minutes and time himself. He does something with his watch and I ask if it will beep. He jokes that actually, it gives him a large shock. We both laugh. He then closes his eyes and starts the exercise. His face looks serene, with no obvious expression of distress.

When time runs out, he said, "That was very hard. I was visualizing different feelings and pictured myself rolling on the floor struggling. " [He grabs both sides of his head, and shows a look of pain on his face, as he acts out what he visualized]. "It's this kind of thing," he said. "That makes me worry about the 'tell'."

(I said, "I understand you worry about that, but actually there was no indication of any feelings on your face while you did it.”)

He seems surprised but not particularly relieved. He then talked about how dramatically his imagination portrayed his reaction to the feelings.

(I said, ’It does seem dramatic and makes me wonder if as much as you don’t want to reveal a 'tell,' there is also a part of you that wants to tell and have someone know.”)

Daniel reacted immediately. "Yes, I think I do," he said. He appears moved and wants to write this idea down. He picks up the book and writes a note in it. There is a pause. more.”)

(I said, "It seems to me you have been approaching and staying with your feelings

Daniel said, “It’s hard, but I think that's true. I’ve been feeling more healthy, less troubled."

[Around here, I'm aware that while I'm connected to where the session is going, I also have a concern that maybe some of what we're talking about is taking us away from further exploring the uncomfortable feelings about closeness with Matt that came up in the last session.] With about 10 minutes left I asked if he has contacted Matt. He said he hadn't.

(I said, "I wonder if you had any further thoughts about what we discussed last time about your concerns you'd be seen as pursuing Matt in sexual way, if you get back to him.”) 
Daniel said no, and seems a bit jarred by the question. "I didn't think of that at all," he said. "I’m not sure what to do...I don't know what to say, what to tell him about the book that I don't like. I don't want to hurt his feelings. I've read 100 pages of the book. I'm not really sure what it's about." He pulled it out of his backpack and showed me [I can't recall the name of it]. He said, "It really has dark themes."

\section{$\underline{\text { Session } 4}$}

Daniel began by reporting that he didn't do much self-care this weekend. He didn't meditate or exercise. Instead, he spent a lot of time procrastinating on writing a cover letter for a job he planned to apply for; though he likes his current job, he's been hoping to find one that involved more time working directly with people and doing less clerical work. As he was writing the letter, he looked at the ad again and it said something about working with brand- new young employees.

He said, “Maybe I like working with older employees, like I do now. These young employees might be too immature. I don't want to be their babysitter.”

(I said, "I wonder if this job fits more or less with the goals you identified as part of the ACT values work. They concern wanting to connect with and help others.”)

“ I'm not sure,” he says, "I'm not even sure I really want to help people as a goal. It was so hard writing the cover letter for the application, mainly because I kept putting it off. It seemed like working on it would be so painful, trying to find the right words that would sound ok. But it ended up being awful because I stayed up so late and didn’t get enough sleep."

(I said, "It seems, like we talked about before, that when you avoid feelings like this you end up feeling worse.”)

Daniel said, "I know about the stuff in the ACT book about willingness to face tough feelings. I realize I'm just scared of moving to a new job. And I don't know enough about how to use the ACT stuff to deal with it. All I want to do is escape, play games all the time. I know that's a form of avoidance. But I don't know what I want to do."

(I asked, “What comes to mind?”)

Daniel said, "I just had a memory of being taken to a drama class as a kid and being very uncomfortable with it, having to present myself to others.”

(“How did you end up doing this?” I asked.)

Daniel said, "I had been in a school play and had done a good job according to people who saw it and they thought I was interested in drama.”

(I said, "There seems to be something important about this memory, because I have never heard you say anything about it in all the time we have been meeting. And it's interesting, because I never had the sense that your parents took you to activities like this.”) 
Daniel agrees it seems significant, but mainly seems uncomfortable about the recollection. To me, it suggests some early shame experiences in which the adults around him didn’t recognize or help him with his discomfort, and these feelings have been maintained for many years.

\section{$\underline{\text { Session } 5}$}

Daniel came in and said, “This hasn't been that great of a week. I'm still thinking about what I really want to do and if I want to try for another job. Maybe I don't want to do anything, just play games. I have been meditating and using the ACT stuff. I tried to accept the idea: "I don't really want to do anything." What if it's true? I was able to let that feeling be there, observe it, not get too flustered...I did run into one of my employees who was upset and needed my help. She was in tears and I was able to calm her. That was good. “

(I said, "It seems that though you accepted the thought that you don't want to do anything and don't have any goals, you also enjoyed helping.” )

“That might be,” Daniel said. "But I also worry about my motives. When I think about helping women, I worry that maybe all I want is to sleep with them, and they might figure this out.”

(I said, “You think they might pick up on some ‘tell’ you worry about?”)

“Exactly,” Daniel responded.

(I said, “Although you worry you only really want to do nothing, just play games, I wonder also if not doing things is a way to avoid the discomfort that comes up when you think of getting more connected with people. Like this woman, there are these sexual feelings that might come up.”)

“That could be,” he said. "Maybe I am avoiding.”

(I said, "You've avoided things like this for so long, it's hard to imagine being able to do them comfortably. I think it might mean you would need to face dealing with the feelings of fear that you don't like. But maybe there is a way you can face them, without them being so overwhelming that you feel you can't handle them. Maybe you can do it using the techniques you've been learning to accept your emotions and thoughts and not feel undone by them.")

He ended the session by saying the thought of doing that is scary, but he is intrigued by the possibility. 


\section{Subsequent Developments}

Following the sessions, above, Daniel struggled to make sense of the ACT approaches to handling his emotions. This period was marked by continued "resistance" 12 to the ACT techniques: he continued to forget to bring his book or read it between sessions. He reported procrastinating and putting off the ACT exercises. He continued to experience painful feelings of self-criticism and concerns about how he came across with others. In these sessions, I wondered to what extent he used the ACT techniques and if not what was getting in the way. A common concern was what would motivate him to do anything if he didn't have an insistent inner critical voice spurring him on.

At these moments, I followed the ACT approach to focusing on valued actions as a motivation to accept and tolerate difficult feelings rather than struggling to make them disappear. At times, this was difficult for Daniel because it was hard for him to be sure what he really valued. When he tried ACT values exercises in which he reviewed various life domains and tried to observe what was most important to him, he identified helping people. But when he struggled with reaching out to people he wondered if this really was a key value of his. He would go back and forth on questions like these for long periods of time.

This sort of ruminative thinking was characteristic of Daniel and seemed to serve as a way to avoid moving forward in treatment and in his life. What was different now was Daniel's grudging willingness - though he complained about how hard the ACT exercises were- to allow himself to feel the troubling feelings by imagining various upsetting scenarios. From an ACT perspective, Daniel was relying less on experiential avoidance but it also seemed that our work involved a traditional behavioral process of imaginal exposure to feared conditioned stimuli-in this instance, Daniel's feelings. In spite of all my efforts over the years to "interpret” his defenses against feelings and encouraging him to "sit with" or "tolerate" them, the ACT framework was allowing him to experience his feelings more directly. His struggles continued so I was surprised several months later when Daniel announced that he and Janice had decided to get married; he was waiting for the ring he ordered to arrive so he could formally propose. It appeared noteworthy that our recent sessions hadn’t involved much discussion of his relationship. Not long afterward, Daniel nonchalantly mentioned that he finally called Matt, they had lunch, and he returned the book. Matt wasn't offended that Daniel didn’t like it.

Given these signs that Daniel was moving forward in his life and had tools to work with on his own when he was faced with difficult feelings, it made sense not long afterwards when he brought up the possibility of us meeting every other week. He proposed this with some trepidation, recalling a time when he had gone off his medication some years ago and became overwhelmed with depression. But Daniel felt comfortable from the outset with the reduced frequency.

\footnotetext{
12 Though resistance is a term associated with psychoanalytic work, therapists from other traditions, including Cognitive Behavioral, have understood the importance of understanding and addressing it (Leahy, 2003).
} 
What precipitated these seemingly sudden changes remains puzzling. From an ACT perspective, practicing present moment awareness and defusing from ruminative thoughts would be expected to increase psychological flexibility and provide freedom in making choices, such as deciding to make a commitment to Janie. Alternatively, introducing this new approach may have communicated something to Daniel about our relationship, perhaps suggesting a commitment on my part to be flexible and be willing to try something outside of my comfort zone in an effort to help him make progress. It could be seen as a form of empathic attunement which Daniel had rarely experienced in previous relationships.

Following this change there was a period of almost a year when Daniel returned to his ruminative concerns about allowing himself to feel difficult feelings and his concern that accepting and not reacting to self-critical thoughts would lead him to do stop performing well at his job or blurt out things that would be embarrassing. The idea that Daniel might try to use ACT to work with these experiences often seemed to be the furthest thing from his mind. When I wondered if he'd tried to defuse from upsetting thoughts or accept his feelings, it sometimes seemed as if he had completely forgotten these techniques. It was almost as if he had dissociated from the part of himself that was making progress. This was quite surprising and frustrating to me, since I felt he was detached from what I had tried to offer him. Perhaps we were stuck all over again.

This continued "resistance” and "experiential avoidance” led me back to my dynamic formulation. I recalled how hard it was for Daniel to move forward and succeed, given his underlying concerns about how his father would react. And I was also aware that experiencing strong feelings reminded Daniel of his out of control father and his fears that he would become like him. Though this was well-trod ground, I tried, when appropriate, to remind him of what we had learned earlier about why he might struggle so much when he started to become successful. In addition to working through previous insights, these comments, I believe, provided an empathic understanding of his struggles and worked against his tendency to castigate himself for not making progress.

Daniel continued his meditation practice during this period and at one point decided he should review parts of the book we had covered before. I suggested at times when he struggled with difficult thoughts and feelings that he pause and mindfully notice his experiences in a nonjudgmental fashion. Almost imperceptibly, I noticed Daniel wasn’t talking about distress any more and consistently reported things going well. One day recently, Daniel observed that he didn’t have much to talk about and thought we should consider terminating. ${ }^{13}$

13 At the time I completed the present case study, Daniel was meeting with me once every three weeks. Things continued to go well, and several months later he decided to end treatment, a process that went smoothly. For some more details on the termination, see the end of my Response to the Commentaries in this same issue of the journal (Cohen, 2016). 


\section{THERAPY MONITORING AND USE OF FEEDBACK INFORMATION}

As mentioned earlier, I didn't use a formal means of seeking feedback. I relied on my reactions to the process and the quality of the relationship. Important information came from times when Daniel's repeated ruminations seemed impervious to my interventions and I became bored or frustrated. Early in the treatment, I reflected on whether I was missing something or had been drawn into an enactment of some transference experience from his past. In retrospect, these periods seem to have been tests of whether I was true to my word about providing him a place where he could express himself however he needed to. Significantly, repeatedly getting into this spot was part of what prompted me to introduce ACT. From a traditional analytic perspective this would have been seen as acting out of the countertransference, an "enactment" that could lead to stalemate if it became protracted (Aron, 1996; Ellman \& Moskowitz, 1998). But I believe this is a narrow and unhelpful understanding of what occurred.

\section{CONCLUDING EVALUATION OF THE THERAPY'S PROCESS AND OUTCOME}

In long therapies when things move slowly, it's sometimes difficult to recognize the extent of changes over time. Sometimes evidence of progress occurs suddenly, as when Daniel announced his intention to get married or his decision to reduce our meetings to every other week. Looking over the whole experience, it's worth recalling that this bright and articulate young man came into therapy after a number of ineffective short-term treatments, struggling with crippling depression, relationship difficulties and work troubles. Over the course of treatment, he was able to end a dissatisfying relationship, find employment in a job where he is highly valued, and begin to establish a group of friends who shared his hobbies. His mood appeared to be fairly stable, and he became increasingly able on his own to manage difficult emotions without avoidance. Currently, he appears to be a devoted husband, prone as is typical in stable marriages to short periods of conflict when he feels criticized by his wife. But these appear to be resolved quickly. While he still ponders whether to find another job or switch careers with some anxiety, he generally feels comfortable with his work life and better able to manage the stress that occurs during busy periods. Increasingly, he has been spending enjoyable time with male friends.

These gains emerged slowly through three phases of therapy. The early, traditional insight-oriented phase, conducted twice weekly, made it possible for Daniel to develop a sense of safety in the therapeutic relationship and to begin to put together a coherent narrative of the early traumatic experiences that contributed to his difficulties.

As my approach became more supportive and less constrained, Daniel was able to experience therapy as a refuge where he reported he felt more comfortable than he had in any other relationship in his life. He also appeared to benefit from an idealized view of me as capable of listening empathically and tolerating whatever difficult experiences he needed to express. The extended time we had worked together by now contributed to a sense of stability, in contrast to his early experiences of chaos at home. Since the intensity of Daniel's symptoms had decreased, we were meeting once weekly. 
When he had improved, but still struggled with difficult moods and ruminative thoughts, the switch to ACT helped Daniel develop the tools to become more comfortable deal with challenging thoughts and feelings. The ACT framework, which was available to Daniel in the workbook and in our sessions, provided the language and techniques to understand what it meant to feel his feelings fully in a way that did not feel dangerous; while I had worked to help him experience his feelings more deeply and comfortably in the psychoanalytic work, it wasn't until I introduced ACT that he was able to grasp what it meant to experience his feelings fully and to recognize the usefulness of doing so. An advantage of the previous dynamic work was my ability to understand and help Daniel in his ACT work by interpreting his resistance to making use of the ACT approach. Also, my willingness to flexibly introduce new techniques to make the therapy more accessible, even if this led me to feel some discomfort, demonstrated my willingness to understand and meet his needs in a way he hadn't experienced much in his formative relationships and modeled my own willingness to be flexible. As should be evident, my work with Daniel was a form of Assimilative Integration: I continued to work within my "home" theory of psychoanalysis, but incorporated ACT to achieve results that couldn't be achieved solely by psychoanalytic means.

Most important, the success of integrating ACT suggests that it is possible to deviate successfully from a standard psychoanalystic approach to respond to specific needs of a patient that aren't met by a reflective, indirect analytic approach. This lesson seems particularly important for many psychoanalytic practitioners who have been reluctant to look outside their theoretical approach to make treatment more effective. As Bateman (2002) states, "Unable to consider new findings and fresh ideas, particularly from cognitive theory and cognitivebehaviour therapy, psychoanalysis is in danger of not only becoming intellectually isolated but also of becoming a body of knowledge uninfluenced by and unable to influence other disciplines (p. 13).”

Bringing together “Third Wave” or Contextual CBT approaches and psychoanalysis, as seen in this case report, is a particularly felicitous pairing. As Steven Hayes (2014), the originator of ACT writes:

Psychodynamic approaches have explored some of the same processes of the spiritual that are being explored in contextual CBT, such as acceptance and mindfulness. The result is a remarkable moment in which psychodynamic and behavioral traditions seem prepared finally to build a productive relationship — one that goes beyond the cartoons each tradition historically made of the other and explores their theoretical and practical overlaps (p. XIX).

While this case and other recent writings demonstrate the usefulness of integrating ACT into psychoanalytic work (Stewart, 2014), it will be interesting to see if ACT practitioners will be open to integrating aspects of contemporary psychoanalytic therapy. I believe they might find two psychoanalytic emphases useful. One is the long-standing focus in psychoanalysis on resistance to aspects of the treatment that patients find threatening. ${ }^{14}$ Another is the continually

${ }^{14}$ Dialectical Behavioral Therapy, another Third Wave approach, emphasizes the importance of addressing resistance, though it has been re-christened “Therapy Interfering Behavior,” consistent with DBT’s roots in behaviorism (Chapman and Rosenthal, 2015). 
evolving understanding in psychoanalysis of the patient-therapist relationship, including how the patient and therapist unconsciously influence each other in ways that can facilitate or limit treatment progress. Though ideas about establishing a sound therapeutic relationship in ACT have been elaborated (Vilardaga and Hayes, 2009), they don't appear to be influenced by clinical psychoanalytic observations.

In spite of the evident progress, it is important to note several caveats about the case. At the time of writing, Daniel was meeting with me once every three weeks with the intent to terminate in the next several months. It remains to be seen whether he will be able to do so, since he is so accustomed to our relationship and may have difficulty relinquishing it. There also has been no follow-up period to see how things progress once we are no longer meeting together. I am hopeful, but also aware that there are some patients who never are able to formally terminate and may continue treatment or return periodically. In an era of quick-fix, short-term therapy, where the more than ten years of work we have done together can feel like an embarrassing anomaly, one might assume that such an outcome would be a failure.

Alternatively, however, it makes sense that in a highly individualistic culture in which family and community ties have frayed and religious associations are on the decline, some individuals will be able to function best if they can remain embedded in a secure attachment relationship. ${ }^{15}$

One lesson of my work with Daniel is the potential costs of narrowly practicing within one's theoretical home theory. Had I known about ACT earlier and was open to implementing its techniques, could Daniel made progress more quickly? It's impossible to know for sure, but the possibility that he could have lived a less inhibited life much sooner is a strong motivation for continued exploration of the kind of integration discussed in this study.

\section{REFERENCES}

Arlow, J. \& Brenner, C. (1964). Psychoanalytic concepts and the structural theory. New York: International Universities Press.

Aron, L. (1996). A meeting of minds: Mutuality in Psychoanalysis. Hillsdale, NJ: Analytic Press. Aron, L. (1991). The patient's experience of the analyst's subjectivity. Psychoanalytic Dialogues, 1, $29-51$.

Bateman, A. W. (2002). Integrative therapy from an analytic perspective. In J. Homes, \& A.W. Bateman (Eds.), Integration in Psychotherapy: Models and Methods (pp. 11-26). NY, Oxford.

\footnotetext{
${ }^{15}$ Some analysts (Kitron, 2014; Levine, 2014) recently have retreated from a once common pejorative attitude towards the "therapeutic lifer." In addition, McWilliams (2015) recently stated: "It has become an unquestioned shibboleth that we need to be identifying treatments that work as fast as possible. In this climate, it feels downright heretical to raise the issue that some individuals are psychologically damaged enough to need ongoing, long-term devotion...After I wrote up one such 'patient for life' many years ago, Donald Peterson, then my dean and hardly an ideologue for endless psychoanalysis, generously told me that he also had several such patients, and so did all his behaviorally oriented colleagues. For some people, I would argue, a life-long attachment may be not only the treatment of choice, but also the longterm cost-effective option in comparison with the price associated with giving them only medication and perfunctory personal attention.”
} 
Brenner, C. (1982). The mind in conflict. New York: International Universities Press.

Blackledge, J. T. (2015). Cognitive defusion in practice: A clinician's guide to assessing, observing, and supporting change in your client (the context press mastering ACT series). Reno, NV: Context Press.

Blagys, M. D., \& Hilsenroth, M. J. (2002). Distinctive activities of cognitive-behavioral therapy: A review of the comparative psychotherapy process literature. Clinical Psychology Review, 22(5), 671-706.

Bresler, J. (2015). Psychotherapy integration: Increasing options in psychoanalysis. In J. Bresler, \& K. Starr (Eds.), Relational psychoanalysis and psychotherapy integration (pp. 79-98). New York: Routledge.

Cabaniss, D. L. (2011). Psychodynamic psychotherapy: a clinical manual. Chichester, UK: Wiley-Blackwell.

Chapman, A. L., \& Rosenthal, Z. R. (2015). Managing therapy-interfering behavior: Strategies from dialectical behavior therapy. Washington, D.C.: American Psychological Association.

Cloud, J. (2006, February 13) The third wave of therapy. Time, 167, 58-64.

Cohen, R. (2016). Expanding my perspective on the case of Daniel. Pragmatic Case Studies in Psychotherapy, 12(1), Article 4, 56-64. Available:pcsp.libraries.rutgers.edu

Cuijpers, P., van Straten, A., Andersson, G., \& van Oppen, P. (2008). Psychotherapy for depression in adults: A meta-analysis of comparative outcome studies. Journal of Consulting and Clinical Psychology, 76(6), 909-922.

de Maat, S., de Jonghe, F., de Kraker, R., Leichsenring, F., Abbass, A., Luyten, P. \& Dekker, J. (2013). The current state of the empirical evidence for psychoanalysis: A meta-analytic approach. Harvard Review Of Psychiatry, 21, 107-137.

Ellman, C. S., Grand, S., Silvan, M., Ellman, S. J. (1999). The modern Freudians: Contemporary psychoanalytic technique. Northville, NJ: Jason Aronson.

Ellman, S.J. and Moskowitz, M. (1998). Enactment: Toward a new approach to the therapeutic relationship. Northville, NJ: Jason Aronson.

Freud, A. (1966). The ego and the mechanisms of defense. New York: International Universities Press. (Originally published in 1936).

Freud, S. (1958). The dynamics of transference. In J. Strachey (Ed \& Trans.), The standard edition of the complete psychological works of Sigmund Freud, (Vol 12), pp. 97-108. (Originally published in 1912).

Gabbard, G. O. (1989). Two subtypes of narcissistic personality disorder. Bulletin of the Menninger Clinic, 53, 527-532.

Gabbard, G.O., Westen, D. (2003). Rethinking therapeutic action. International Journal of Psychoanalysis, 84, 823-841.

Gerber, Andrew J. , Kocsis, J. H., Milrod, B. L., Roose, S. P., Barber, J. P., Thase, M. E.,\& Leon, A. C. (2011). A quality-based review of randomized controlled trials of psychodynamic psychotherapy. The American Journal of Psychiatry, 168,19-28.

Greenberg, J. R. \& Mitchell, S. A. (1983). Object relations in psychoanalytic theory. Cambridge, MA: Harvard University Press.

Harris, R. (2009). ACT made simple: An easy-to-read primer on acceptance and commitment therapy. Oakland, CA: New Harbinger Publications. 
Hayes, S. C. (2014). Forward. In J. M. Stewart (Ed.), Mindfulness, acceptance, and the psychodynamic evolution (pp. 17-20). Oakland, CA: Context Press.

Hayes, S. C. (2004). Acceptance and commitment therapy, relational frame theory, and the third wave of behavioral and cognitive therapies. Behavior Therapy, 35(4), 639-665.

Hayes, S. C., Follette, V. M., \& Linehan, M. (2004). Mindfulness and acceptance: Expanding the cognitive-behavioral tradition. New York: Guilford Press.

Hayes, S. C (2005). Get out of your mind and into your life: the new Acceptance \& Commitment Therapy. Oakland, CA: New Harbinger Publications.

Hoffman, I.Z. (2009). Doublethinking our way to "Scientific" legitimacy: The desiccation of human experience. Journal of the American Psychoanalytic Association, 57 (5), 10431069.

Hoffman, I. Z. (1983). The patient as interpreter of the analyst's experience. Contemporary Psychoanalysis, 19, 389-422

Jacobs, T. J. (2013) The possible profession: The analytic process of change. New York: Routledge.

Kahl, K. G., Winter, L., \& Schweiger, U. (2012). The third wave of cognitive behavioural therapies: What is new and what is effective? Current Opinion in Psychiatry, 25(6), 522528.

Kanter, J., Tsai, M., Kohlenberg, R. J., \& SpringerLink (2010). The practice of functional analytic psychotherapy. New York, NY: Springer .

Kitron, David. (2014). Interminability as a legitimate need. Psychoanalytic Inquiry, 34, $20-27$.

Kohlenberg, R. J., \& Tsai, M. (1991). Functional analytic psychotherapy: Creating intense and curative therapeutic relationships. New York: Plenum Press.

Kohut, H. (1971). The analysis of the self: A systematic approach to the psychoanalytic treatment of narcissistic personality disorders. Chicago: University Of Chicago Press.

Leahy, R. (2003). Overcoming resistance in cognitive therapy. New York: The Guilford Press.

Leichsenring F, Rabung S. (2011). Long-term psychodynamic psychotherapy in complex mental disorders: update of a meta-analysis. British Journal of Psychiatry, 199, 15-22.

Lemma, A., \& Patrick, M. (2010). Off the couch: Contemporary psychoanalytic approaches. London: Routledge.

Levine, A. S., \& Faust, J. (2013). A psychodynamic approach to the diagnosis and treatment of closet narcissism. Clinical Case Studies, 12(3), 199-212.

Levine, H. B. (2014). The puzzle of interminable treatments. Psychoanalytic Inquiry, 34(1), 419.

Levy, R.A. \& Ablon, S.J. (Eds.) (2009). Handbook of evidence-based psychodynamic psychotherapy: bridging the gap between science and practice. New York: Humana Press.

Lindon, J. A. (1994). Gratification and provision in psychoanalysis: Should we get rid of the “rule of abstinence?” Psychoanalytic Dialogues, 4,549-582.

Linehan, M. (1993). Cognitive-behavioral treatment of borderline personality disorder. New York: Guilford Press.

Loewald, H. (1960). On the therapeutic action of psychoanalysis. International Journal of Psychoanalysis, 58, 463-472. 
McWilliams, N. (2015). Integrative research for integrative practice: A plea for respectful collaboration across clinician and researcher roles. Paper Presented at Annual Meeting of the Society for the Exploration of Psychotherapy Integration, Baltimore, MD.

Messer, S. B. (1992). A critical examination of belief structures in integrative and eclectic psychotherapy. In J. C. Norcross \& M. R. Goldfried (Eds.), Handbook of psychotherapy integration (pp. 130-165). New York: Basic Books.

Messer, S.B. (2001). Introduction to the special issue on assimilative integration. Journal of Psychotherapy Integration, 11, 1-4.

Miller, W. R. \& Rollnick, S. (2012). Motivational Interviewing (3 ${ }^{\text {rd }}$ Ed.). New York: The Guilford Press.

Neimeyer, R. A., \& Mahoney, M. J. (Eds.). (1999). Constructivism in Psychotherapy. Washington, DC: American Psychological Association.

Norcross, J.C. \& Goldfried, M. R. (Eds.). (2005). Handbook of psychotherapy integration (2 ${ }^{\text {nd }}$ ed.). New York: Oxford University Press.

Northcut, T. B., \& Heller, N.R. (1999). Enhancing psychodynamic therapy with cognitivebehavioral techniques Northvale, N.J: Jason Aronson.

Pilecki, B., Thoma, N., \& McKay, D. (2015). Cognitive behavioral and psychodynamic therapies: Points of intersection and divergence. Psychodynamic Psychiatry, 43(4), 463490.

Pulver, S. E. (1992). Psychic change: Insight or relationship? International Journal of Psychoanalysis, 73, 199-208

Renik, O (1993). Analytic interaction: Conceptualizing technique in light of the analyst's irreducible subjectivity. Psychoanalytic Quarterly, 62, 553-571.

Renik, O. (1995). The ideal of the anonymous analyst and the problem of self-disclosure. Psychoanalytic Quarterly, 64, 466-495.

Ryle, A., \& Kerr, I. B. (2002). Introducing cognitive analytic therapy principles and practice. Chichester, England: John Wiley \& Sons.

Schafer, R. (1994). Retelling a life: Narration and dialogue in psychoanalysis. Basic Books: New York.

Shanok, A.F. (2015) Driving me sane: Integrating CBT and Relational Psychodynamic Psychotherapy. In J. Bressler, \& K. Starr (Eds.), Relational psychoanalysis and psychotherapy integration (pp. 59-78). New York: Routledge.

Shedler J. (2010). The efficacy of psychodynamic psychotherapy. American Psychologist, 65, 98-10

Spence, D. (1982). Narrative truth and historical truth. New York: Norton.

Stewart, J.M. (2014). Mindfulness, acceptance, and the psychodynamic evolution: Bringing values into treatment planning and enhancing psychodynamic work with Buddhist psychology. Context Press, Oakland, CA.

Stern, D.N., Sander, L.W, Nahum, J.P., Harrison A.M., Lyons-Ruth, K., Morgan, A.C., Bruschweiler-Stern, N. \& Tronick, E.Z .(1998). Non-interpretive mechanisms in psychoanalytic therapy: The something more than interpretation. International Journal of Psychoanalysis, 79:903-21.

Stone, L. (1981). Notes on the noninterpretive elements in the psychoanalytic situation and process. Journal of the American Psychoanalytic Association, 29, 89-118.

Strachey, J. (1934). The nature of the therapeutic action of psycho-analysis. International 
Journal of Psychoanalysis, 15, 127-159.

Stricker, G. (2006). Assimilative Psychodynamic Psychotherapy Integration. In G. Stricker \& J. Gold (Eds.), A casebook of psychotherapy integration (pp. 55-63). Washington, DC: American Psychological Association.

Sugarman, A. (2006). Mentalization, insightfulness, and therapeutic action: The importance of mental organization. International Journal of Psychoanalysis, 87, 965-87.

Summers, F. (2012). Psychoanalysis, the tyranny of objectivism, and the rebellion of the subjective. International Journal of Applied Psychoanalytic Studies, 9 (1), 35-47.

Summers, R.F. \& Barber, J. P (2009). Psychodynamic therapy: A guide to evidence-based practice. New York: The Guilford Press.

Valliant, G. E. (1998). The wisdom of the ego. Cambridge, MA: Harvard University Press.

Vilardaga, R. \& Hayes, S.C. (2009). Acceptance and Commitment Therapy and the therapeutic relationship stance. European Psychotherapy, 9, 1-23.

Wachtel, P. L. (1977). Psychoanalysis and behavior therapy. New York: Basic Books.

Wachtel, P.L. (2008). Relational theory and the practice of psychotherapy. New York, NY: Guilford Press.

Wachtel, P. L. (2011a). Inside the session: What really happens in psychotherapy. Washington, DC, US: American Psychological Association.

Wachtel, P.L. (2011b). Therapeutic communication: Knowing what to say when ( ${ }^{\text {nd }}$ ed.). New York: The Guilford Press.

Wallerstein, R. (1989). The psychotherapy research project of the Menninger Foundation: An overview. Journal of Clinical and Consulting Psychology, 57, 195-205. 